Revised checklist for suspected malignant melanoma

Major signs

Minor signs

Change in size

Inflammation

Change in shape

Change in colour

Crusting or bleeding

Sensory change

Diameter $\geqslant 7 \mathrm{~mm}$

three major and four minor signs (see box). The major signschange in size, shape, and colour of a new or pre-existing cutaneous lesion - were seen in 94,95 , and 89 of the 100 lesions studied, and none failed to show one of the major signs. The 100 lesions included the elusive amelanotic, usually nodular, melanoma, which is often misnamed as most have a peripheral rim of pigment. Amelanotic melanomas are usually excised because of change in size or shape. The remaining four features -inflammation, crusting or bleeding, sensory change, and diameter (which has been reduced to 7 $\mathrm{mm}$ )-are found in combination more often than in nonmelanoma pigmented lesions, but they are less often present individually, with inflammation seen in 51 , sensory change in 46 , and crusting or oozing in 31 . Our current recommendation is, therefore, that a patient with a pigmented lesion with any one of the major signs should be considered for referral and that the presence of any of the minor signs should be a further stimulus to referral. It is also important to recognise that patients themselves may often not be aware of any of the six signs and that relatives or friends often note the changes and encourage consultation with the general practitioner. This is particularly true of men, possibly because the commonest site for melanoma in men is the back.

Once again I must emphasise that these are guidelines, and no lesions causing anxiety should be excluded from referral on the basis of this or any other checklist. It may well be easier, however, for family doctors themselves to offer reassurance on the basis of these guidelines, thus avoiding the need for referral.

The content of referral letters and purpose of the referral to our clinic has become much clearer over the past five years, and most letters now state concisely which features of the lesion have prompted referral, the patient's degree of concern,

and whether early melanoma is truly suspected or additional reassurance is the main purpose of referral. This allows accurate triage of referral letters at busy times, but even then no patient waits longer than three weeks to be seen. It remains to be established whether or not further refinements of this type of guideline can increase specificity with no loss of sensitivity in referral.

Additional aids to clinical recognition include the skin surface microscope or its less expensive cousin, the dermatoscope, and computerised image analysis. The first two instruments depend on recognising, in vivo, at moderate magnification, and under good lighting, features of the pigment distribution pattern in melanoma that are not seen in non-melanoma pigmented lesions. Over 25 years' personal experience with this suggests that the accuracy will not be greater than $85 \%,,^{67}$ a figure identical to that quoted recently by Grin et $a l^{8}$ for diagnostic accuracy based on clinical assessment. The use of computerised image analysis is being studied in several centres, and stored images will probably give a very good indication of change in a lesion previously assessed, such as a dysplastic naevus undergoing observation, though absolute diagnosis will be more elusive. Both the skin surface microscope and the computer are expensive and time consuming in use. They will therefore be found only in specialist centres, and simple guidelines such as the seven point checklist, revised and updated as new data become available, will continue to offer practice guidelines for the public and for family doctors.

Professor of Dermatology,

RONA M MACKIE

University of Glasgow,

Glasgow G11 6NU

1 Osterlind A, Jensen OM. Incidence of trunk melanoma in young Danish women. Br 7 Cancer 1987:55:467-72.

2 MCLeod GR. Control of melanoma in high risk populations. In: Elwood JM, ed Pigment cell. Vol 9. Basle: Karger, 1988:131-9.

Doherty VR, MacKie RM. Experience of a public education programme on early detection of cutaneous malignant melanoma. Br.Med f 1988;297:388-91.

Mac Kie RM. An illustrated guide to the recognition of early malignant melanoma. Glasgow: University Department of Dermatology, 1985

MacKie RM. Malignant melanoma. A guide to eurly diagnosis. (ilasgow: University Department of Dermatology, 1989.

6 MacKie RM. An aid to the preoperative assessment of pigmented lesions of the skin. Br 7 Dermatol 1971:85:232-8.

Anonymous. Skin surface microscopy. Anything new under the sun? [Editorial]. Lancet 1989;i:1239. 8 Grin CM, Kopf AW, Welkovich B, Bart RS, Levenstein MJ. Accuracy in the clinical diagnosis of malignant melanoma. Arch Dermatol 1990;126:763-6.

\title{
Do streptococci cause toxic shock?
}

\section{Possibly}

The toxic shock syndrome came to prominence as "tampon disease" and is caused by exotoxins of Staphylococcus aureus. Now a similar syndrome has been linked with erythrogenic toxin A of group A $\beta$ haemolytic streptococci. ${ }^{2}$. Of the three such toxins, toxin $A$ is particularly associated with the rash of scarlet fever. In recent decades it has been found infrequently in both Britain ${ }^{3}$ and the United States, ${ }^{+}$but it was present in strains originally isolated before the second world war. ${ }^{3}$ Can group A streptococci now produce toxin A more commonly, and does it produce toxic shock?

The decline in importance of group A streptococci in developed countries is usually attributed to improved social conditions and antibiotics, but changes in the distribution of serotypes and in toxin production may also have played a part. ${ }^{5}$ Recent events in streptococcal disease demonstrate this and do not allow complacency. Outbreaks of rheumatic fever in the United States have been associated with $M$ type 18, still not a common serotype. In 1988 notifications of scarlet fever in Britain rose, as did the incidence of the associated $M$ type 4 among strains sent to the Streptococcus Reference Laboratory. ${ }^{6}$ The number of group A strains isolated from patients with bacteraemia by the laboratory in 1975-88 increased in parallel with the general increase in reporting of positive blood cultures.

The two clinical reports of toxic shock syndrome apparently associated with group A toxin A are suggestive: among the 22 patients with serious documented group A streptococcal infection, 21 were hypotensive, 18 had renal impairment, and seven died. ${ }^{12}$ Nine of the 12 strains examined produced toxin A. This was not a point source outbreak as different serotypes 
were implicated and the patients were separated in time and place. In contrast with staphylococcal toxic shock syndrome, an erythematous rash was uncommon in these patients and many had obvious soft tissue infection and bacteraemia. That three quarters of the organisms produced toxin $\mathrm{A}$ is surprising and important, but its association with toxic shock is incomplete. Gram positive bacteraemia itself may lead to shock, and fulminating infections have been reported with $\beta$ haemolytic streptococci of other groups that do not produce toxins. ${ }^{89} \mathrm{~A}$ survey of group A strains from serious infections in Britain failed to detect toxin $\mathrm{A},{ }^{10}$ but in a changing scene fresh data are always needed."

Toxin A might well be responsible for certain clinical effects. It enhances shock induced by endotoxins, ${ }^{12}$ it induces tumour necrosis factor, ${ }^{13}$ and its protein sequence resembles that of the enterotoxin B of Staph aureus that is associated with toxic shock syndrome. ${ }^{14}$ Whatever its role in pathogenicity, the gene controlling its production seems to be located on a phage (bacterial virus) that may infect group A streptococci and switch on toxin production. ${ }^{15} 16$ This is how Corynebacterium diphtheriae acquires toxigenicity, and it might account for a change in frequency of production of toxin $\mathrm{A}$ independently of changing serotypes.

The clinical message is that fulminating infection with severe hypotension may be caused by haemolytic streptococci. ${ }^{1718}$ Shock of uncertain origin in a previously well patient, especially when there is skin sepsis, may be due to group A strains that are producing toxins. Blood cultures and swabs of local lesions, throat, and vagina should be taken and isolates examined for serotype and toxins if possible. Benzylpenicillin is the antibiotic of choice, but it may be difficult clinically to exclude staphylococcal toxic shock syndrome, for which the appropriate antibiotic is fluclox- acillin. This is active against group A streptococci, albeit some 10 -fold less so than penicillin. As in cellulitis, the best choice in these circumstances is a combination of the two antibiotics.

Consultant Microbiologist,

Edgware General Hospital,

Edgware,

Middlesex HA8 0AD

PHILIP SANDERSON

1 Stevens DL, Tanner $M H$, Winship J, et al. Severe group A streptococcal infections associated with a toxic shock-like syndrome and scarlet fever toxin A. N Engl f Med 1989;321:1-7.

Cone LA, Woodard DR, Schlievert PM, Tomory GS. Clinical and bacteriologic observations of a toxic shock-like syndrome due to Streptococcus pyogenes. N Engl F Med 1987;317:146-9.

Hallas G. The production of pyrogenic exotoxins by group A streptococci. foumal of Hygiene (Cambridge) 1985;95:47-57.

Schlievert PM, Bettin KM, Watson DW. Production of pyrogenic exotoxin by groups of streptococci: association with group A. F Infect Dis 1979;140:676-81.

5 Stollerman GH. Changing group A streptococci: the reappearance of streptococcal "toxic shock." Arch Intern Med 1988;148:1268-70.

6 Communicable Disease Surveillance Centre. Streptococcal infections: group A streptococcal infections and scarlet fever. Communicable Disease Report 1989; No 46

7 Communicable Disease Surveillance Centre. Surveillance of streptococcal infections: bacteraemia and meningitis 1975-88. Communicable Disease Report 1990; No 26.

8 Barnham M. Rapidly fatal group B and G streptococcal infections in adults. I Infect 1980;2:279-81. 9 Cruickshank JG, Hart RJC, George M, Feest TG. Fatal streptococcal septicaemia. BMJ 1981;282:1944-5.

10 Gaworzewska ET, Hallas G. Group A streptococci infections and a toxic shock-like syndrome. N Englf Med 1989;321:1546.

11 Gaworzewska ET, Colman G. Changes in the pattern of infection caused by Streptococcus pyogenes. Epidemiol Infect 1988;100:257-69.

2 Toshimi M, Yoshiyuki O, Hironoshin K, Seizaburo K. Physiology of the potention of lethal endotoxin shock by streptococcal pyrogenic exotoxin in rabbits. Infect Immun 1987;55:2456-60.

13 Fast DJ, Schlievert PM, Nelson RD. Toxic shock syndrome-associated staphylococcal and Fast DJ, Schlievert PM, Nelson RD. Toxic shock syndrome-associated staphylococcal and
streptococci pyrogenic toxin are potent inducers of tumor necrosis factor production. Infect Immun 1989;57:291-4.

14 Johnson LP, Le Italien JJ, Schlievert PM. Streptococcal pyrogenic exotoxin type A (scarlet fever toxin) is related to Staphylococcus aureus enterotoxin B. Mol Gen Genet 1986;203:354-6.

15 Nida SK, Ferretti JJ. Phage influence on the synthesis of extracellular toxins in group A streptococci. Infect Immun 1982;36:745-50.

16 Johnson LP, Schlievert PM. Group A streptococcal phage T12 carries the structural gene for pyrogenic exotoxin type A. Mol Gen Genet 1984;194:52-6.

17 Ispahani P, Donald FE, Aveline AJD. Streptococcus pyogenes bacteraemia: an old enemy subdued but not defeated. F Infect 1988;16:37-46.

8 Francis J, Warren RE. Streptococcus pyogenes bacteraemia in Cambridge - a review of 67 episodes. Qf Med 1988;68:603-13.

\section{Sexual expression in paraplegia}

\section{Is possible and should be encouraged}

At first sight, the loss of sexual fulfilment may seem a minor consequence of spinal cord injury when set against the profound loss of autonomy caused by the paralysis. Certainly it is not always judged to be of prime importance. ${ }^{12}$ Nevertheless, when a healthy active man or woman is turned into a cripple overnight the retention of self esteem is critical, as is the need to retain the support and affection of a partner, whose caring role may be vital. For both these reasons the loss of potency in men and sexual responsiveness in women may be the final straw. A recent paper by Slot et al, however, suggests that in men, at least, pessimism is unjustified.

Erection is largely mediated through the parasympathetic fibres originating from S2-S4 (T12 vertebral level), and genital sensations are received at the same level. Seminal emission is mediated through the sympathetic fibres at T11L2 (T11 vertebral level), though ejaculation and orgasm lie at S2-S4. Lesions of the cauda equina remove all except seminal emission, while lesions above T11 allow reflex erections ${ }^{4}$ : "The higher the lesion the greater the likelihood of ejaculation. Orgasm and ejaculation are more vulnerable than erection."

Several papers have described the practical effects of such lesions..$^{5-8}$ Slot et al reported on the sexual capacity of 38 men with static lesions confined to wheelchairs. ${ }^{3}$ Thirty six had erections, 25 sufficient for coitus, and 17 could expel semen. The lower the lesion the greater its effect on erection, but 12 could obtain psychogenic erections, two of whom appeared to have complete lesions of the cervical cord. Though good, these results are in line with those of other studies, except for the high figure for ejaculation, which is usually present in only $10 \%,{ }^{9}$ though higher if assisted by, for example, a vibrator.

The return of some function emphasises the importance of counselling the patient and his partner to enable this function to be used. Sexual behaviour is private and patients may be reluctant to introduce the subject, so the initiative must lie with the doctor. There is a balance to be struck between implying on the one hand that sexual expression is essential for a healthy life, thereby increasing the burden on those without adequate function or a partner, and on the other hand treating sex with such circumspection that it remains unmentionable. Schuler suggests that counselling should consist of education (about the timing and prospects of recovery and sexual mechanisms), encouraging a change of attitude (to passivity in men and communication of sexual needs within the relationship), ${ }^{10}$ and practical advice about techniques ${ }^{11}$ and aids (including intracavernosal injections of papaverine). ${ }^{12}$

The normal loss of erections after the injury should not discourage the patient. Talbot found that half the men who eventually recovered potency had had no erections in the first three months, ${ }^{13}$ while Phelps et al showed that improvement may continue for up to two years (with a mean of nine months). ${ }^{5}$ Even when an erection is unattainable, however, experimenting with alternative sexual techniques may be 